\title{
KONTRUKSI KALIMAT SINGKAT BAHASA SUNDA (Kajian Struktur dan Makna Kalimat dalam Majalah Manglẻ)
}

\author{
Wiwin Setiawati, Yayat Sudaryat \\ SMPN 1 Cihampelas \\ Pos-el: wiwinnya@gmail.com, yayat.sudaryat@upi.edu
}

\begin{abstract}
Abstrak
Penelitian ini bertujuan untuk mengetahui dan mendeskripsikan kalimat singkat dalam majalah Manglé. Dalam penelitian ini digunakan metode deskriptif. Data dikumpulkan melalui teknik studi pustaka dengan instrumen kartu data. Untuk mengolah data digunakan teknik analisis unsur langsung. Hasil penelitian menemkan 706 kalimat singkat yang frekuensi pemakaiannya sebanyak 2028 kalimat. Ditemukan enam tipe kalimat singkat, yakni kalimat salam, kalimat seruan, kalimat panggilan, kalimat judul, kalimat motto, dan kalimat inkripsi. Kalimah singkat memiliki pola tertentu, yakni A : Kal Sal $\rightarrow \mathrm{P}+\mathrm{S} \pm \mathrm{K}$; B : Kal Seru $\rightarrow \mathrm{S} \pm \mathrm{P} ; \mathrm{C}:$ Kal Pangg $\rightarrow$ Kata Seru; D : Kal Jud $\rightarrow \mathrm{S} \pm$ O; E : Kal Mot $\rightarrow$ FP/FS Koor; F : Kal Ins $\rightarrow$ FB N + FB Mod. Kalimat singkat mengandung sepuluh makna, yakni rasa syukur, ucapan selamat, seruan pengganti dan nama diri, rasa sakit, marah, menerima, kaget, pernyataan, pedoman, dan cita-cita.
\end{abstract}

Kata kunci: kalimat singkat, struktur, fungsi, makna

\section{THE CONSTRUCTION OF SUNDANESE SIMPLE SENTENCES (The Study of Structure and Meaning of Sentences in The Manglẻ Magazine)}

\begin{abstract}
This study was to identify and to describe simple sentences in Mangle magazine. This study used a descriptive method. The data were collected through library research technique with data card instrument. The data processing employed direct elemental analysis technique. The research found 706 sentences with the use frequency of 2028 sentences. This study found six types of simple sentences. They are the greetings, appeals, callings, titles, motto, and encryptions. A simple sentence has a certain pattern, namely $A: K a l$ Sal $\rightarrow P+S \pm K ; B$ : Kal Seru $\rightarrow S \pm P ; C:$ Kal Pangg $\rightarrow$ Kata Seru; D : Kal Jud $\rightarrow S \pm O ; E:$ Kal Mot $\rightarrow$ FP/FS Koor; F : Kal Ins $\rightarrow$ FB $N+F B$ Mod. The simple sentence contains ten meanings: gratitude, congratulations, calling for a replacement, and the name of self, pain, anger, acceptance, surprise, statements, guidance, and ideals.
\end{abstract}

Keywords: Simple Sentence, Structure, Function, Meaning.

\section{PENDAHULUAN}

Bahasa Sunda merupakan bahasa ibu bagi orang Sunda dan sekaligus menjadi bahasa daérah di Jawa Barat. Kedudukan bahasa Sunda sebagai bahasa daerah tercantum dalam UUD 1945, Bab XV, penjelasan pasal 36. Juga dalam kesimpulan Seminar Politik Bahasa Nasional di Jakarta (1975) dan dalam RUU kebahasaan (2006). Dalam kedudukannya sebagai bahasa daerah, bahasa Sunda berfungsi sebagai (1) lambang kebanggaan daerah, (2) lambang identitas daerah, (3) alat komunikasi di lingkungan keluarga dan masyarakat daerah, (4) pendudung bahasa nasional, (5) bahasa pengantar di SD pada kelas-kelas permulaan di Jawa Barat, dan (6) alat untuk mengembangkan dan mendukung budaya Sunda (Halim dalam Sudaryat, 2007). 
Untuk memperkuat legitimasi bahasa Sunda, Gubernur Jawa Barat mengeluarkan Perda Nomer 5 tahun 2003 tentang Pemeliharaan Bahasa, Sastra, dan Aksara Daérah. Sebagai wujud atau realisasi dalam bidang pendidikan dan pengajaran, Gubernur Jawa Barat mengeluarkan surat keputusan No.423.5/Kep.674-Disdik/2006 tanggal 25 Juli 2006 tentang Standar Kompeténsi dan Kompeténsi Dasar serta Panduan Penyusunan Kurikulum Tingkat Satuan Pendidikan Mata Pelajaran Bahasa dan Sastra Sunda TK/RA, SD/MI, SMP/MTS, SMA/MA/SMK. Kemudian pada tahun 2013, Gubernur Jawa Barat mengeluarkan keputusan No.69, Tahun 2013 tentang Kompeténsi Inti dan Kompeténsi Dasar Mata Pelajaran bahasa dan sastra Sunda. Hal ini sesuai dengan rekomendasi UNESCO tahun 1999 tentang pemeliharaan bahasa-bahasa ibu di dunia, yang pada tanggal 21 Pebruari ditetapkeun menjadi "Hari Bahasa Ibu Internasional".

Bahasa Sunda lahir bersamaan dengan lahirnya masyarakat Sunda serta budayanya. Oleh karena itu, dalam kehidupannya masyarakat Sunda mengadakan komunikasi dengan bahasa Sunda sebagai alat komunikasnya. Bahasa Sunda tidak hanya digunakan untuk menjalin interaksi sosial saja, tetapi digunakan pula untuk diri sendiri. Untuk diri sendiri bahasa Sunda digunakan ketika kita bermimpi, berdoa, bergumam, menghitung, dan membuat catatan harian dalam agenda pribadi. Sementara, bahasa Sunda yang digunakan sebagai alat komunikasi adlah bahasa Sunda yang digunakan untuk mengirim dan menerima pesan (perasaan, pikiran, dan kehendak) dari penyapa kepada pesapa melalui medium bahasa. Bahasa Sunda digunakan pada waktu berkomunikasi, yakni sebagai alat bergaul dengan sesama orang Sunda atau bukan orang Sunda yang telah mampu berbahasa Sunda.

Di dalam proses komunikasi, penutur dapat mengekspresikan apa saja yang dirasakan, baik rasa gembira, sedih, atau marah kepada mitra tutur. Ekspresi perasaan, pikiran, dan kehendak dalam sitem bunyi ketika pergaulan disebut struktur batin atau isi bahasa (deep structure). Sementara, sistem bunyi manusia yang dihasilkan melalui alat ucap manusia disebut struktur ahir (surface structur). Hal yang dikomunikasikan oleh penutur kepada mitra tutur diungkapkan dalam bentuk kalimat. Kalimat merupakan konstruksi yang digunakan untuk mengungkapkan isi komunikasi; perasaan, pikiran, dan kehendak.

Kalimat yang digunakan pada waktu komunikasi ada yang bentuknya lengkap ada yang tidak lengkap. Konstruksi kalimat yang lengkap maupun tak lengkap dapat ditemukan dalam berbagai medium komunikasi. Kedua konstruki kalimat itu ketika digunakan dalam komunikasi dapat berupa medium lisan dapat berupa medium tulisan. Medium bahasa lisan pada umumnya digunakan ketika berbincangbincang sehari-hari, mengajar, berceramah atau pidato, sedangkan medium bahasa tulis digunakan dalam majalah, koran, dan bukubuku karya sarta pengajaran.

Penelitian ini memusatkan perhatian kepada kalimat singkat dalam ragam bahasa tulis yang ditemukan dalam majalah berbahasa Sunda, yakni majalah Manglé. Penelitian mengenai struktur bahasa Sunda memang sudah banyak dilakukan, baik yang berkaitan dengan subsistem fonologis, subsistem gramatikal (morfologi dan sintaksis), maupun subsistem leksikal. Penelitian yang berkaitan dengan struktur kalimat sebagai subsistem gramatikal relatif sudah banyak. Akan tetapi, penelitian yang mengkaji kalimat singkat bahasa Sunda masih jarang dilakukan. Penelitian ini bertujuan untuk mengetahui dan mendeskripsikan struktur danmakna kalimat singkat bahasa Sunda yang terdapat dalam majalah Manglé. Deskripsinya meliputi empat hal, yakni (1) bentuk kalimat singkat, (2) tipe kalimat singkat, (3) struktur kalimat singkat, dan (4) makna kalimat singkat dalam majalah Manglé. 


\section{METODE}

Dalam penelitian ini digunakan pendekatan kualitatif dengan metode deskriptif. Metode déskriptif digunakan untuk mendeskripsikaun salah satu gejala, kejadian yang dialami pada waktu penelitian berlangsung dengan mengungkapkan hal-hal yang menjadi pusat analisis agar menghasilkan paparan yang jelas (Sukmadinata, 2009; Sugiono, 2013) mengenai struktur dan makna kalimat singkat dalam majalah Manglé. Deskripsinya meliputi empat hal, yakni (1) bentuk kalimat singkat, (2) tipe kalimat singkat, (3) struktur kalimat singkat, dan (4) makna kalimat singkat dalam majalah Manglé.

Sumber data dalam penelitian ini adalah majalah Manglé selama empat edisi, yang terbit minggu pertama sampai minggu keempat bulan Nopember tahun 2014, yakni No. 2499, 2500, 2501, dan 2502. Data kalimat singkat dijaring dari seluruh rubrik majalah Mangle, yakni (1) Lawang Sakéténg, (2) Kaca Tilu, (3) Koropak, (4) Tamu, (5) Laporan, (6) Kolom, (7) Nyusur Galuh, (8) Munara Cahaya, (9) Tanya Jawab, (10), Aweuhan Pasundan, (11) Gedong Saté, (12) Katumbiri, (13) Balé Bandung, (14) Tarucing Cakra, jeung (15) Lempa Lempi Lempong.

Untuk mengumpulkan data digunakan teknik studi dokumentasi, studi pustaka atau studi bibliografi. Instrumen yang digunakan adalah sistem kartu data. Dalam kartu data disajikan informasi tentang alafabeti data, data kalimat singkat, sumber data, halaman, paragraf, dan urutan kalimat. Setelah data terkumpul, kemudian diolah dengan menggunakan teknik analisis unsur langsung.

\section{HASIL DAN PEMBAHASAN}

Penelitian ini menemukan bahwa kalimat singkat bahasa Sunda dalam Majalah Manglé ada 706 yang frekuensi pemakaiannya sebanyak 208 kalimat. Kalimat singkat tersebut dapat dilihat dari segi tipe, struktur, dan maknanya.

\section{Tipe Kalimat Singkat}

Tipe kalimat singkat merupakan klasifikasi kalimat singkat dilihat dari bentuk dan fungsinya waktu komunikasi. Sesuai dengan landasan teori (Tarigan, 1985) serta data yang telah dikumpulkan, ditemukan enam tipe kalimat singkat, yakni (1) kalimat salam, (2) kalimat seruan, (3) kalimat panggilan, (4) kalimat judul, (5) kalimat motto, dan (6) kalimat inkripsi. Keenam tipe kalimat singkat tersebut masing-masing dipaparkan sebagai berikut.

\section{1) Kalimah Salam}

Kalimat salam mengacu kepada kalimat singkat yang isinya dan fungsinya digunakan untuk mengungkapkan salam kepada mitra tutur. Kalimat salam pada umumnya digunakan pada waktu bertemu untuk memulai pembicaraan dan pada waktu berpisah untuk menutup pembicaraan. Tujuannya untuk mempererat tali silaturahim. Berdasarkan hasil analisis data ditemukan sebanyak 18 kalimat salam, antara lain, terlihat pada contoh data berikut.

\section{(01) Alhamdulillah1 (M 2501/35/4/1) \\ (02) Asalamualaikum Wr Wb! (M 2499/16/1/1) \\ (03) Damang Nyi Mangél! (M 2499/4/1/1) \\ (04) Kumaha tah? (M 2499/37/10/1)}

Pada data di atas tampak bahwa kalimat salam merupakan kalimat singkat yang digunakan untuk memulai dan mengakhir pembicaraan. Kalimat (01) untuk mengungkapkan rasa syukur, kalimat (02)-(03) untuk mengungkapkan salam, dan kalimat (04) untuk mengungkapkan rasa terima kasih.

2) Kalimat Panggilan

Kalimat panggilan mengacu kepada kalimat singkat yang isina digunakan untuk memanggil nama orang, gelar, pangkat, kekerabatan, sebutan, dan kata ganti. Berdasarkan hasil analisis data ditemukan 44 kalimat seruan, antara lain, terlihat pada cotoh data berikut. 
(05) Aa! (M 2500/34/1/2)

(06) Abah! (M 2502/26/2/1)

(07) Abah Ihin! (M 2499/20/16/2)

Pada data di atas tampak bahwa kalimat seruan merupakan kalimat singkat yang digunakan untuk memangil kata ganti dan kekerabatan $(05,06)$ dan menyerukan kekerabatan dan nama orang (07).

\section{3) Kalimat Seruan}

Kalimat seruan mengacu kepada kalimat ringkas yang digunakan untuk mengungkapkan suara hati, perasaan, dan emosi seperti perasaan gembira, kaget, jengkel, marah, dsb. Berdasarkan hasil analisis data iteukan sebanyak 85 kalimat panggilan, antara lain, terlihat pada contoh dta berikut.

(08) Aaaah! (M 2501/36)

(09) Abong! (M 2501/56/35)

(10) Alaah! (M 2500/27/6/1)

(11) Amiin! (M 2499/56/11/15)

Berdasarkan data di atas tampak bahwa kalimat serua merupakan kalimat singkat yang isinya mengungkapan suara hati, yakni rasa kaget $(08,09)$, rasa jengkel (10), dan rasa syukur (11).

\section{4) Kalimat Judul}

Kalimat judul mengacu kepada kalimat titel seperti buku, majalah, dan koran atau judul-judul di dalam buku, majalah, dan koran. Kalimat judul pada umumnya berupa kata atau frasa. Apabila kalimat judul diikuti dengan penulisnya yang membentuk frasa preposisional $k u$ dan nama diri, maka kalimat judul tersebut membentuk kalimat preposisonal. Berdasarkan hasil analisis data ditemukan sebanyak 131 kalimat judul, antara lain, terlihat pada contoh data berikut.

(12) $1955,2014, \mathrm{Ku}$ AM

(13) Ampir Kasarung di Lembur

(14) Sanglingan, ku Tatang Sumarsono

(15) APBD Parobahan Kudu Keuna Kana Sasaran, Ku Cucu/Dede
Berdasarkan data di atas terlihat bahwa kalimat judul merupakan kalimat singkat yang berisi titel dan nama penulisnya $(12,14,15)$, keduali kalimat judul (13) tanpa penulisnya. Judul berupa frasa nominal yang diikuti frasa preposisional ku dan nama orang.

\section{5) Kalimat Motto}

Kalimat motto mengacu kepada kalimat singkat yang isinya dan fungsinya sebagai pedoman dalam kehidupan dalam menggapai cita-cita. Berdasarkan hasil analisis data ditemukan sebanyak 17 kalimat motto, antara lain, terlihat pada data sebagai berikut.

(16) Bener, jujur, pengkuh (M 2502/89/8/12)

(17) Henteu Degig, Teu Perengih (M 2502/37/14/22)

(18) Hirup Bari Jeung Hurip
Salawasna. (M 2502/99/14/8)

Pada data di atas terlihat bahwa kalimat motto merupakan kalimat singkat yang berisi pedoman hidup dalam menggapai cita-cita. Kalimat $(16,17)$ mengungkapkan nilai karakter, sedangkan kalimat (18) menggambarkan filosofis hidup.

\section{6) Kalimat Inkripsi}

Kalimat inkripsi mengacu kepada kalimat singkat yang isinya berupa ucapanucapan yang ditujukan kepada seeorang sebagai tanda kasih sayang, penghormatan, terima kasih, dan bakti. Dari hasil analisis data ditemukan enam kalimat inskripsi, antara lain, tampak pada contoh data berikut.

(19) Kanyaah ka sarakan! (M 2500/1/2/1)

(20) Kanyaah téh tembong tina pangaruhna! (M 2501/1/2/3)

(21) Kanyaahna ngamumulé budya Sunda (M 2501/44/1/6) 
Pada data di atas terlihat bahwa kalimat inskripsi merupakan kalimat singkat yang digunakan untuk mengungkapkan 'tanda kasih sayang' dan 'penghormatan'.

\section{Struktur Kalimat Singkat}

Kalimat singkat dapat dilihat dalam wacana yang ditentukan berdasarkan situasi, biasanya diakhiri dengan intonasi final. Kalimat singkat mengacu kepada kalimat yang ukurannya pendek, pada umumnya struktur kalimatnya pun tidak sempurna. Sebagaimana telah diuraikan bahwa kalimat singkat memiliki enam tipe, yakni kalimat salam, kalimat seruan, kalimat panggilan, kalimat judul, kalimat motto, dan kalimat inskripsi. Setiap subtipe kalimat singkat memiliki struktur tertentu, yang dilihat berdasarkan unsur fungsionalnya seperti subyek, predikat, obyek, pelengkap, dan keterangan.

\section{1) Struktur Kalimat Salam}

Struktur kalimat salam mengacu kepada pola-pola kalimat yang lazim digunakan sebagai pembuka dalam memulai pembicaraan atau sebagai penutup pada waktu mengakhiri pembicaraan. Struktur kalimat salam dapat dipolakan sebagai berikut.

\section{Pola A : Kal Sal $\rightarrow \mathrm{P}+\mathrm{S}+\mathrm{K}$}

Kalimat salam dibentuk dengan predikat dan subyek, baik diikuti keterangan maupun tidak. Mungkin saja hanya dibentuk oleh keterangan saja. Pola A ini memiliki tiga subpola sebagai berikut.

\section{Pola A1 : Kal Sal $\rightarrow$ K}

Pola A 1 merupakan kalimat salam yang dibentuk oleh sebuah keterangan. Kalimat ini termasuk kalimat singkat dan tak lengkap seperti tampak pada contoh data berikut.

(22) Alhamdulillah (M 2501/35/4/1);

(23) Nuhun. (M 2500/42/13/4)

Pola A2: Kal Sal $\rightarrow \mathrm{P}+\mathrm{K}$
Pola A2 merupakan kalimat salam yang dibentuk dengan satu predikat dan satu keterangan. Kalimat ini termasuk kalimat singkat dan tak lengkap seperti tampak pada contoh data berikut.

(24) Assalamu'alaikum Wr Wb. ( M 2499/4/1/1)

(25) (589) Salam Baktos.

(M 2499/4/1/1)

\section{Pola A3: Kal Sal $\rightarrow \mathrm{P}+\mathrm{S}$}

Pola A3 merupakan kalimat salam yang dibentuk dengan satu predikat dan subyek. Kalimat ini termasuk kalimat singkat dan tak lengkap seperti tampak pada contoh data berikut.

(26) Damang nyi Mangle! (M 2499/4/1/1);

(27) Wilujeung angkat kang. (M 2499/31/27/18);

\section{2) Struktur Kalimat Seruan}

Struktur kalimat seruan atau vokatif merupakan kalimat singkat yang digunakan untuk menyerukan nama, gelar, pangkat, orang, perkerabatan, sebutan, dan kata ganti. Struktur kalimat seruan dapat dipolakan sebagai berikut.

\section{Pola B : Kal Seru $\rightarrow \mathrm{S} \pm \mathrm{P}$}

Kalimat seruan dibentuk oleh subyek saja, atau subyek dan predikat. Kalimat seruan termasuk kalimat singkat dan tak lengkap. Pola B ini memiliku dua subpola sebagai berikut.

\section{Pola B1 : Kal Seru $\rightarrow$ S}

Pola B1 merupakan kalimat seruan yang dibentuk dengan satu subyek. Subyek dalam kalimat seruan pada umumnya berupa nama diri dan sesebutan yang digunakan sebagai seruan seperti terlihat pada contoh data berikut.

(28) Aa. (M 244/37)

(29) Bapa. (M 2499/10/8/10)

(30) Dosen. (2501/52/4/9) 
Pola B2: Kal Seru $\rightarrow$ P + S

Pola A3 merupakan kalimat seruan yang dibentuk dengan satu predikat dan subyek. Kalimat seruan yang memiliki subyek dan predikat tergolong ke dalam kalimat sempurna seperti tampak pada contoh data berikut.

(31) Bupati Purwakarta. (M 2499/52/2/2);

(32) Capres Prabowo-Hatta Raharja. (M 2499/43/5/1); (33) Guru Besar UIN.( M
2500/7/6/10);

\section{3) Struktur Kalimat Panggilan}

Kalimat panggilan mengacu kepada kalimat singkat yang isinya merupakan cetusan hati, perasaan, atau emosi penutur seperti perasaan gembira, kaget, jengkel, dan marah. Struktur kalimat panggilan dapat dipolakan sebagai berikut.

\section{Pola C: Kal Pangg $\rightarrow$ Kata Seru}

Pola C merupakan kalimat pangilan yang dibentuk oleh unsur keterangan. Kata atau frasa yang mengisi unsur keterangan laimnya berupa kata atau ungkapan seruan, ajakan, dan adverbia waktu. Perhatikan contoh data berikut.

(34) Aaaah. (M 2501/36)

(35) Abong. (M 2501/56/35)

(36) Alaah. (M2500/27/6/1)

(37) Amin. (M 2499/56/11/15)

\section{4) Struktur Kalimat Judul}

Struktur kalimat judul mengacu kepada judul buku, majalah, Koran, artikel, atau kagiatan. Kalimat ini pada umumnya berbentuk kata atau frasa. Struktur kalimat judul dapat dipolakan sebagai berikut.

$$
\text { Pola D : Kal Jud } \rightarrow \mathrm{S} \pm \mathrm{O}
$$

Kalimah judul dibentuk dengan subyek saja atau subyek dan obyek, lazimnya predikat diisi dengan kata kerja "disusun" atau "dikarang" yang dihilangkan, diikuti oleh frasa preposisional $k u$ dan nomina nama orang. Struktur kalimat judul memiliki dua subpola sebagai berikut.

Pola D1 : Kal Jud $\rightarrow$ S

Kalimah judul dibentuk dengan subyek saja tanpa obyek seperti terlihat pada contoh data berikut.

(38) Aweuhan Pasundan. (M 2499/41)

(39) Bale Bandung. (M 2499/54)

(40) Munara Cahaya. (2501/14)

$$
\text { Pola D2: Kal Ju } \rightarrow \mathrm{S}+\mathrm{O}
$$

Pola D2 merupakan kalimat judul yang dibentuk dengan satu subyek dan obyek. Subyeknya berupa nomina atau frasa nominal, sedangkan objeknya berupa frasa preposisional yang tersusun dari preposisi $k u$ dan nomina nama diri. Perhatikan contoh data berikut.

(41) 1955, 2014, ku AM.(M 2499/3);

(42) Anugrah KPID Jawa Barat 2014, ku Taufik. (M 2499/50);

(43) Asih Dina Kapeurih, ku Jéjén Jaélani Wargadipura. (M 2500/22);

\section{5) Struktur Kalimat Motto}

Struktur kalimat motto mengacu kepada kalimat yang berisi pedoman hidup dalam mencapai cita-cita. Struktur kalimat motto dapat dipolakan sebagai berikut.

\section{Pola E : Kal Mot $\rightarrow$ FV / FAdj (koordinatif)}

Pola ini merupakan kalimat motto yang dibentuk oleh frasa verbal atau frasa adjektival, baik tunggal maupun gabungan. Struktur kalimat motto memiliki tiga subpola sebagai berikut.

\section{Pola E1 : Kal Motto $\longrightarrow$ FV}

Pola E1 merupakan kalimat motto yang dibentuk dengan verba atau frasa 
verbal, baik berbentuk tunggal maupun berbentuk gabungan. Perhatikan contoh data berikut.

(44) Hurip Sunda. (M 2500/46/7/13);

(45) kiruh ti girang kiruh ka hilir. (M 2499/7/10/18);

Pola E2 : Kal Motto $\longrightarrow$ FP Kod

Pola E2 merupakan kalimat otto yang dibentuk oleh frasa verbal koordinatif. Frasa verbal koordinatif tersebut dibentuk dari dua verba atau lebih yang dihubungkan dengan konjungsi, atau verba dengan adverbia sebagai atribut. Perhatikan comtoh data berikut.

(46) hirup bari jeung hurip salawasna. (M 2502/99/14/8);

(47) mun butuh supana, kudu daék miara catangna. (M 3501/7/6/3);

(48) Nanjung dina tuturus nu luhung. (M 2499/85/7/3);

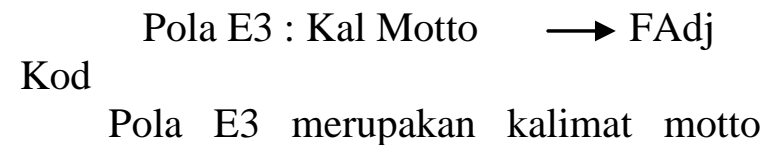
yang dibentuk dengan frasa adjektival koordinatif seperti terlihat pada contoh data berikut.

(49) Bener, jujur, pengkuh. (M 2502/89/8/12)

(50) Obah, robah, turta pinanggih barokah.(M 2502/41/9/17)

(51) Kiruh ti girang kiruh ka hilir. (M 2499/7/10/18)

\section{6) Struktur Kalimat Inkripsi}

Struktur kalimat inkripsi merupakan ucapan-ucapan yang ditunjukkan sebagai tanda kasih sayang, bakti, penghormatan, dan tanda jasa. Struktur kalimat inskripsi dapat dipolakan sebagai berikut.

Pola F : Kal Ins $\rightarrow \mathrm{FN} \pm$ FPrep

Pola F merupakan kalimat inkripsi yang dibentuk dengan frasa nominal dan frasa preposisional, yang tersusun dari preposisi $k a$ dan nomina. Perhatikan contoh data berikut.

$\begin{array}{llll}\text { (52) Kanyaah } & \text { ka } & \text { sarakan. } & \text { (M } \\ \text { 2500/1/2/1); } & & & \\ \text { (53) Kanyaah } & \text { ka } & \text { sasama. } & \text { (M } \\ \text { 2500/6/7/19); } & & & \end{array}$

\section{Makna Kalimat Singkat}

Makna kalimat singkat merupakan makna atau isi yang dimiliki oleh kalimat singkat. Setiap tipe kalimat singkat memiliki makna masing-masing seperti diuraikan sebagai berikut.

\section{1) Makna Kalimah Salam}

Makna kalimat salam merupakan makna kalimat singkat yang berisi ungkapan salam kepada mitra tutur pada waktu bertemu atau berpisah. Ditemukan dua makna kalimat salam, yakni rasa syukur dan ucapan selamat.

(a) Makna 'Rasa Syukur'

Makna 'rasa syukur' menunjukkan kalimat salam yang berisi 'rasa syukur' kepada Allah Swt seperti terlihat pada contoh data berikut.

(54) Alhamdulillah. (M 2501/35/4/1);

(55) Nuhun. (M 2500/42/13/4);

(b) Makna 'Ucapan selamat'

Makna 'ucapan selamat' menunjukkan kalimat salam yang berisi 'ucapan selamat' dari penutur kepada mitra tutur seperti terlihat pada contoh data berikut.

(56) Asalamualaikum $\mathrm{Wr} \mathrm{Wb}$. (M 2499/4/1/1)

(57) Wilujeng milangkala. (M 2502/4)

2) Makna Kalimat Panggilan

Makna kalimat panggilan merupakan makna kalimat singkat yang berisi panggilan nama diri, gelar, pangkat, kekerabatan, sebutan, dan kata ganti. Terdapat dua makna kalimat panggilan, 
yakni makna 'seruan pengganti' dan 'seruan nama diri'.

(a) Makna 'panggilan pengganti'

Makna 'panggilan pengganti'

merupakan makna kalimat singkat yang menunjukkan panggilan berupa kata ganti seperti terlihat pada contoh data berikut.

(58) Abah. (M 2502/26/2/1);

(59) Akang. (M 2499/23/16/6);

(b) Makna 'panggilan nama'

Makna 'panggilan nama' merupakan makna kalimat singkat yang menunjukkan panggilan berupa nama diri seperti terlihat pada contoh data beikut.

(60) Abah Iawan (M 2499/6/1/6);

(61) Abah Iwan Abdulrahman (M 2499/6/5/2);

\section{3) Makna Kalimat Seruan}

Makna kalimat panggilan merupakan makna kalimat singkat yang berisi suara hati yang mengungkapkan isi hati, perasaan, atau emosi seperti perasan gembira, kaget, jengkel, dan marah. Ditemukan tiga makna kalimat seruan, yakni 'kesakitan', 'marah', dan 'menerima'.

(a) Makna 'Seruan kesakitan'

Makna 'seruan kesakitan' merupakan maknakalimat singkat yang berisi 'seruan kesakitan' seperti terlihat pada contoh data berikut.

(62) Aaaah. (M 2501/36);

(63) Alaah. (M2500/27/6/1);

(b) Makna 'seruan marah'

Makna 'seruan marah' merupakan makna kalimat singkat yang berisi 'seruan marah' seperti terlihat pada contoh data berikut.

(64) Abong (M 2501/56/35);

(65) Sok (M 2501/29/14/1);

(c) Makna 'Seruan menerima'

Makna 'seruan menerima' merupakan makna kalimat singkat yang berisi 'seruan menerima' apa yang diungkapkan seperti terlihat pada contoh data berikut.

(66) Amin Yaa Robbal Alamin. (M 2501/15/20/5);

(67) Sawangsulna. (M 2499/29/18/1);

(d) Makna 'Seruan Kaget'

Makna 'seruan kaget' merupakan makna kalimat singkat yang berisi ungkapan 'seruan kaget' seperti tampak pada comtoh data berikut.

(68) Ambuing. (M 2501/56/52)

(69) Walakadalah. (M 2501/56/43)

(70) Wah. (M 2500/34/1)

4) Makna Kalimat Judul

Makna kalimat judul mengacu kepada kalimat singkat yang berisi 'berita' atau 'informasi' seperti terlihat pada contoh data berikut.

(71) 1955, 2014, ku AM. (M 2499/3)

(72) Anugrah KPID Jawa Barat 2014, ku Taufik (M 2499/50)

\section{5) Makna Kalimat Motto}

Makna kalimat motto mengacu kepada makna kalimat singkat yang berisi pedoman hidup dan cita-cita. Terdapat dua mkan kalimat motto, yakni 'pedoman' dan 'citacita'.

(a) Makna Motto 'Pedoman'

Makna motto 'pedoman' mengacu kepada makna kalimat singkat yang berisi 'pedoman hidup' manusia seperti terlihat pada contoh data berikut.

(73) Bener, jujur,pengkuh. (M 2502/89/8/12)

(74) Henteu padengung, teu adigung. (M 2502/37/14/8)

(b) Makna Motto 'Cita-cita'

Makna motto 'cita-cita' mengacu kepada makna kalimat singkat yang berisi 'cita-cita' seseorang seprti terlihat pada contoh berikut. 
(75) Hirup Bari Jeung Hurip Salawasna (M 2502/99/14/8)

(76) Obah, robah, turta pinanggih barokah. (M 2502/41/9/17);

\section{6) Makna Kalimat Inkripsi}

Makna kalimat inskripsi mengacu kepada makna kalimat singkat yang berisi ucapan-ucapan-ucapan kepada seseorang sebagai tanda kasih sayang, penghormatan, dan kebaktian. Perhatikan contoh data berikut.

(77) Kanyaah ka sarakan. (M 2500/1/2/1);

(78) Kanyaah téh tembong tina pangaruhna. (M 2501/1/2/3);

Wujud bahasa terkecil yang digunakan untuk menyatakan pikiran, perasaan, dan kehendak adalah kalimat. Pada waktu berkomunukasi, kalimat dapat berbentuk panjang dapat berbentuk singkat. Kalimat yang bentuknya panjang pada umumnya berupa kalimat sempurna dan lengkap. Sebaliknya, kalimat yang pendek lazimnya berupa kalimat singkat, baik sengaja disusun pendek maupun sengaja disingkat.

Kalimat singkat dapat ditemukan dalam medium bahasa lisan maupun medium bahasa tulis. Sebagai salah satu bentuk medium tulisan, dalam majalah Manglé ditemukan 706 kalimat singkat dengan frekuensi pemakaiannya sebanyak 2.028 kalimat. Berdasarkan hasil analisis data ditemukan enam tipe kalimat singkat, yakni (1) kalimat salam, (2) kalimat seruan, (3) kalimat panggilan, (4) kalimat judul, (5) kalimat motto, dan (6) kalimat inkripsi. Setiap tipe kalimat singkat memiliki struktur dan makna masing-masing seperti tampak pada tabel berikut.

Tabel 1: Tipe, Struktur, dan Makna Kalimat Singkat

\begin{tabular}{|c|c|c|c|}
\hline No. & Tipe & Struktur & Makna \\
\hline \multirow[t]{3}{*}{1.} & Kalimat salam & A1 : Kal Sal $\rightarrow$ K & 1. 'Rasa syukur' \\
\hline & & $\mathrm{A} 2: \mathrm{Kal} \mathrm{Sal} \rightarrow \mathrm{P}+\mathrm{K}$ & 2. 'Ucapan selamat' \\
\hline & & $\mathrm{A} 3: \mathrm{Kal} \mathrm{Sal} \rightarrow \mathrm{P}+\mathrm{S}$ & \\
\hline \multirow[t]{2}{*}{2.} & Kalimat Panggilan & B1 : Kal Pangg $\rightarrow \mathrm{S}$ & 1. 'Panggilan ganti' \\
\hline & & B2 : Kal Pangg $\rightarrow \mathrm{P}+\mathrm{S}$ & 2. 'Panggilan nama' \\
\hline \multirow[t]{4}{*}{3.} & Kalimat Seruan & $\mathrm{C}:$ Kal Seru $\rightarrow$ Kata seru & 1. 'Kesakitan' \\
\hline & & & 2. 'Marah' \\
\hline & & & 3. 'Menerima' \\
\hline & & & 4. 'Kaget' \\
\hline \multirow[t]{2}{*}{4.} & Kalimat judul & D1 : Kal Jud $\rightarrow$ S & 'Berita' atau \\
\hline & & D2 : Kal Jud $\rightarrow \mathrm{S}+\mathrm{O}$ & 'informasi' \\
\hline \multirow[t]{3}{*}{5.} & Kalimat motto & E1 $:$ Kal Motto $\rightarrow$ FV & 1. 'Pedoman' \\
\hline & & E2 $:$ Kal Motto $\rightarrow$ FV Kod & 2. 'Cita-cita' \\
\hline & & E3 $:$ Kal Motto $\rightarrow$ FAdj Kod & \\
\hline 6. & Kalimat Inskripsi & F $:$ Kal Ins $\rightarrow$ FN + FPrep & 'Tanda kasih' \\
\hline
\end{tabular}

Berdasarkan tabel di atas tampak bahwa kalimat singkat memiliki enam tipe, yakni kalimat salam, kalimat seruan, kalimat panggilan, kalimat judul, kalimat motto, dan kalimat inkripsi (Sudaryat, 2007). Masingmasing tipe kalimat singkat memiliki fungsi yang berbeda-beda. Kalimat salam mengacu kepada kalimat singkat yang isinya dan fungsinya digunakan untuk mengungkapkan salam kepada mitra tutur pada awal dan akhir pertemuan dengan tujuan untuk mempererat tali silaturahim. Kalimat panggilan mengacu kepada kalimat singkat yang isina digunakan untuk memanggil nama orang, gelar, pangkat, kekerabatan, sebutan, dan kata ganti. Kalimat seruan mengacu kepada kalimat ringkas yang digunakan untuk 
mengungkapkan suara hati, perasaan, dan emosi seperti perasaan gembira, kaget, jengkel, marah, dsb. Kalimat judul mengacu kepada kalimat titel seperti buku, majalah, dan koran atau judul-judul di dalam buku, majalah, dan koran. Kalimat motto mengacu kepada kalimat singkat yang isinya dan fungsinya sebagai pedoman dalam kehidupan dalam menggapai cita-cita. Kalimat inkripsi mengacu kepada kalimat singkat yang isinya berupa ucapan-ucapan yang ditujukan kepada seeorang sebagai tanda kasih sayang, penghormatan, terima kasih, dan bakti.

Kalimat singkat beserta tipe-tipenya memiliki struktur tertentu. Struktur kalimat singkat mengacu kepada unsur fungsional kalimat seperti subyek, predikat, obyek, pelengkap, dan keterangan. Karena ukurannya pendek, struktur kalimat singkat pada umumnya tidak lengkap. Ditemukan 12 pola kalimat singkat, yakni (1) A1 : Kal $\mathrm{Sal} \rightarrow \mathrm{K}$; (2) A2 : Kal Sal $\rightarrow \mathrm{P}+\mathrm{K}$; (3) A3 $: \mathrm{Kal} \mathrm{Sal} \rightarrow \mathrm{P}+\mathrm{S}$; (4) B1 : Kal Seru $\rightarrow \mathrm{S}$; (5) B2 : Kal Seru $\rightarrow \mathrm{P}+\mathrm{S}$; (6) $\mathrm{C}: \mathrm{Kal}$ Pangg $\rightarrow$ Kata Seru; (7) D1 : Kal Jud $\rightarrow$ S; (8) D2 : Kal Jud $\rightarrow \mathrm{S}+\mathrm{O}$; (9) E1 :Kal Motto $\rightarrow \mathrm{FV}$; (10) E2 :Kal Motto $\rightarrow \mathrm{FV}$ Kod; (11) E3 : Kal Motto $\rightarrow$ FAdj Kod; (12) F : Kal Ins $\rightarrow$ FN + FPrep.

Dilihat dari segi semantik, kalimat singkat beserta tipenya memiliki makna tertentu. Dari enam tipe kalimat singkat ditemukan 11 makna, yakni (1) 'rasa syukur', (2) 'ucapan selamat', 'panggilan pengganti' (4) 'panggilan nama', (5) 'kesakitan', (6) 'rasa marah', (7) 'menerima', (8) 'rasa kaget', (9) 'berita', (10) 'pedoman', dan (1) 'cita-cita'. Makna 'rasa syukur' mengungkapkan bersyukur kepada Allah Swt karena mendapat kebahagiaan. Makna 'ucapan selamat' berisi ekspresi ucapan selamat ketika awal dan akhir pertemuan untuk mempererat tali silaturahim. Makna 'menerima' berisi ungkapan penerimaan terhadap keadaan yang dialami penutur. Makna 'rasa kaget' berisi ungkapan perasan kaget karena mengalami ketidaksenangan. Makna 'informasi' berisi ungkapan berita dari penutur kepada mitra tutur. Makna 'pedoman' berisi ungkapan yang berupa pedoman hidup. Makna 'cita-cita' berisi ungkapan tentang tujuan yang akan dicapai oleh penutur.

\section{SIMPULAN}

Berdasarkan hasil analisis dan deskripsi data dapat disimpulkan beberapa hal berikut.

a. Kalimah singkat dalam majalah Manglé merupakan kalimat yang pada umumnya berukuran pendek. Jumlahna ada 706 yang frekuensi pemakaiannya sebanyak 2.028 kalimah.

b. Kalimat singkat memiliki enam tipe, yakni kalimat salam, kalimat seruan, kalimat panggilan, kalimat judul, kalimat motto, dan kalimat inkripsi.Kalimah singget memiliki pola tertentu.

c. Kalimat singkat memiliki struktur tertentu. Ditemukan 12 pola kalimat singkat, yakni (1) A1 : Kal Sal $\rightarrow \mathrm{K}$; (2) A2 : Kal Sal $\rightarrow$ P + K; (3) A3 : Kal Sal $\rightarrow \mathrm{P}+\mathrm{S}$; (4) B1 : Kal Seru $\rightarrow \mathrm{S}$; (5) B2 : Kal Seru $\rightarrow$ P + S; (6) C : Kal Pangg $\rightarrow$ Kata Seru; (7) D1 : Kal Jud $\rightarrow$ S; (8) D2 $:$ Kal Jud $\rightarrow$ S + O; (9) E1 :Kal Motto $\rightarrow$ FV; (10) E2 :Kal Motto $\rightarrow$ FV Kod; (11) E3 : Kal Motto $\rightarrow$ FAdj Kod; (12) F : $\mathrm{Kal}$ Ins $\rightarrow$ FN + FPrep.

d. Kalimat singkat memiliki makna tertentu. Ditemukan 11 makna, yakni (1) 'rasa syukur', (2) 'ucapan selamat', (3) 'panggilan pengganti' (4) 'panggilan nama', (5) 'kesakitan', (6) 'rasa marah', (7) 'menerima', (8) 'rasa kaget', (9) 'berita', (10) 'pedoman', dan (1) 'citacita'.

Berdasarkan simpulan di atas terdapat beberapa saran yang perlu dikemukakan.

a. Penelitian ini hanya menganalisis kalimat singkat yang berasal dari medium tertulis, yakni Majalah Manglé. Masih perlu penelitian kalimat singkat yang sumber datanya dari medium bahasa lisan. 
b. Penelitian ini bersifat kualitatif yang mengkaji data kalimat singkat secara murni. Oleh karena itu, perlu penelitian kalimat singkat yang diterapkan dalam pembelajaran di sekolah. Penelitian ini adalah penelitian kualitatif yang bersifat murni. Meskipun demikian, semoga tulisan ini dapat dijadikan sebagai salah satu alteratif bahan ajar pembelajaran bahasa Sunda.

\section{PUSTAKA RUJUKAN}

Sudaryat, Yayat. 2007. Tata Basa Sunda Kiwari. Bandung: Penerbit Yrama Widya.

Sugiyono. 2013. Metode Penelitian Pendidikan Pendekatan Kuantitatif,
Kualitatif dan $R \& G$. Bandung: Penerbit Alfabeta

Sukmadinata, Nana Syaodih. 2009. Metode Penelitian Pendidikan. Bandung: Remaja Rosdakarya.

Tarigan, Henry Guntur. 1985. Pengajaran Sintaksis. Bandung: Angkasa.

\section{UCAPAN TERIMA KASIH}

Penulis mengucapkan terima kasih kepada Dr. H. Yayat Sudaryat, M.Hum. yang telah membimbing tesis ini dengan penuh kesabaran. Tidak luput pula ucapan terima kasih dan penghargaan penulis sampaikan kepada penyunting Jurnal Lokabasa yang telah memuat tulisan ini. 